\title{
Grid Frequency Control. Secondary Frequency Control Tuning taking into account Distributed Primary Frequency Control.
}

\author{
J. L. Agüero (*) IEEE Senior Member, M. C. Beroqui (*) and F. Issouribehere (*) IEEE Member
}

\begin{abstract}
A new method developed and applied to tune Secondary Control Loop (SCL) for grid frequency control is presented.

The presented method is based on an equivalent representation of all active distributed Primary Control Loop (PCL) in the grid for frequency control.

The characteristic of each PCL is associated to prime mover and its governors: Hydraulic, gas or steam.

The equivalent model of distributed PCL takes into account all active representative composition of PCL in the grid for each typified power flow (seasons, working/not-working day, peak/valley, morning/afternoon/night, etc).

By this way, each equivalent model of distributed PCL allows to find the best tuning of SCL for each typified power flow.

This method was applied to tune the SCL of Yacyretá, a hydraulic power plant with 20 Kaplan turbines of $155 \mathrm{MW}$ each one.

Yacyretá is one of the power plants that have SCL in the "Sistema Argentino de Interconexión" (SADI), the largest power grid of Argentina.
\end{abstract}

Index Terms- Frequency control. Governors. Primary Frequency Control. Secondary Frequency Control. Spinning reserve. Turbines.

\section{NOMENCLATURE}

AGC Automatic Generation Control of a power plant

AJC Automatic Joint Control of Electrical Power of a power plant

F Frequency

F SP Frequency Set Point

FPC: Frequency Primary Control.

FSC: $\quad$ Frequency Secondary Control

PE Electrical Power

PM Mechanical Power

PCL: Primary Control Loop

SCL: Secondary Control Loop.

\section{INTRODUCTION}

I mbalance between demand and generation gives rise to variations in the kinetic energy accumulated in the spinning masses of the whole grid, resulting in variations of frequency.

To keep generation and demand balanced, the coarse action is based on estimating or predicting the demand for the next hour and put in service the necessary generation.

Not predicted demand variations and/or untimely shutdowns of generators or of other equipment involved in grid operation may also alter the load-generation balance.

The goal of the frequency control is to keep demand and

This work was partially supported by Ente Binacional Yacyretá (EBY) (*) J. L. Agüero, M. C. Beroqui and F. Issouribehere are with IITREE-LAT. Facultad de Ingeniería Universidad Nacional de La Plata. (1900) 48 y 116. La Plata. Argentina (e-mail: iitree@iitree-unlp.org.ar). generation balanced at all times, by automatically producing the generation changes needed to achieve this balance.

The FPC aims to adapt quickly the generated power to the demand. This causes small changes in many units over the system.

For the FPC operation, it is not only necessary that governors work appropriately but also it is necessary to have immediate available spinning reserve. The aim of FSC is to ensure the reserve for the proper operation of FPC. The FSC is performed alternatively by one of three or four big hydraulic power plants. Yacyretá with 20 Kaplan turbines of $155 \mathrm{MW}$ each is one of them.

This paper describes the utilized method to adjust the FSC of Yacyretá power plant.

\section{GRID FREQUENCY CONTROL}

Fig. 1 displays a simplified block diagram of the grid frequency control. This block diagram is only valid to obtain the mean value of grid frequency in the long term. The grid frequency control has the following variables: Electrical Power (PE), Frequency (F), Frequency Set Point (F SP) and Mechanical Power (PM) of generators.

The grid frequency control has the following blocks: Grid Load, Grid Spinning Masses, Distributed Primary Control Loop, Secondary Control Loop and Tertiary Control Loop.

\section{A. Grid Load}

Block "Grid Load" of Fig. 1 represents the total Electrical Power (PE) of grid loads.

\section{B. Grid Spinning Masses}

Block "Grid Spinning Masses" of Fig. 1 represents the rotating masses equation of the whole system.

\section{Distributed Primary Control Loop}

For short times, from a few seconds to several minutes, the active turbine governors react modifying turbines mechanical power to correct frequency grid when a frequency deviation takes place.

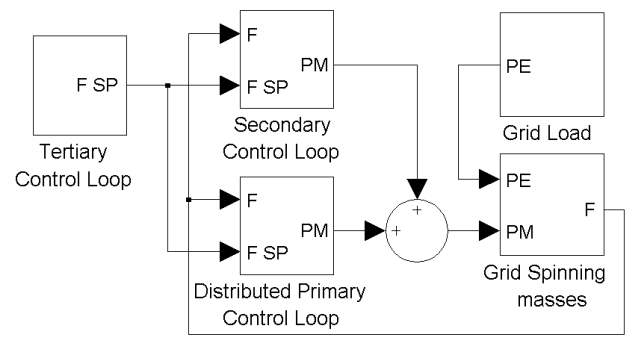

Fig. 1: Grid Frequency Control. Simplified Block Diagram. 